\title{
A CONCEPTUAL FRAMEWORK FOR EFFICIENT NEW PRODUCT INTRODUCTIONS
}

\author{
Erik Sandin', Mauro Onori ${ }^{2}$ \\ 'esn@iip.kth.se \\ ${ }^{2}$ WoxénCentrum \\ Dept. of Production Engineering \\ The Royal Institute of Technology \\ Stockholm, Sweden \\ onori@iip.kth.se
}

\begin{abstract}
Increasing global competition, decreasing lifecycles and outsourcing trends put new demands on product design and assembly system development. These demands call for highly flexible assembly systems, consisting of standardised, process-oriented assembly modules, offering robust processes and high equipment reuseability. To generate such a system, a new concept for crossfunctional development of products and the assembly system is being developed. The concept is based on a distinct connection between product design and the assembly system. To achieve this, the Assembly Module Platform (AMP) is being developed. The AMP generates the Module Process Description (MPD), which defines the process executed by the modules. The design of the product can now be guided by the MPD, creating a processoriented product design.
\end{abstract}

\section{INTRODUCTION}

The major problems incurred by companies dealing with assembly all relate to uncertainty. First of all, it is very difficult for companies to predict the type and range of products that will have to be developed. The second uncertainty regards the production volumes and lifespans reached by these future products. The overwhelming reaction to these problems has been to attempt to develop extremely flexible assembly machines that attempt to adapt themselves to different product families and production scenarios. This has led to a series of multi-purpose machines, amongst which the MarkI, MarkII and MarkIII Flexible Automatic Assembly (FAA) cells developed at our premises [1]. Another approach has been to focus on the standardisation and modularisation of high-volume manual assembly lines [2], also resulting in special robotic cells for the automatic tasks. Flexibility, instead of the actual assembly process, has been the core issue of most of these developments. This fact has been further aggravated by the fact that a firm grasp of 
which type of flexibility is being targeted has, until recently [3], been neglected in favour of a general description of this term. Unfortunately, this existing paradigm of highly flexible (automatic) assembly systems still prevails, resulting in expensive, highly technological solutions ([4],[5]) which cannot easily fit into existing production facilities are seldom able to assemble more than one product generation. In reality, however, $90-95 \%$ of producing companies have to deal with planned products and existing production facilities. Ideally, they would like to fit any new product into an existing assembly system with as low costs as possible. To date, this has only been a dream. The common scenario is that the existing production system principles still dictate, to a varying degree, the basic design requirements for future products, and vice versa. Basically, there is a strong dependence between product development and selected system principle (parallel flow, serial line, etc.). This entails that any new FAA, or other assembly system solution, has to fit into an existing facility. For example, as soon as a given product design leads to a potential assembly system solution, a serious analysis of the components is required to ensure that the targeted volumes, costs, etc. are attained. This often leads to a change in some system component, or product part, to enable the achievement of the goals. This is exactly where the problems arise: the maximum attainable capacity and flexibility of an assembly system are ultimately dictated by the product design and assembly equipment [6]. Therefore, if the equipment cannot easily adapt to changing market requirements and/or new products, the overall flexibility is greatly reduced. Furthermore, if the envisaged FAA solution cannot easily fit into the existing production system scenario, it will not be deemed as fully flexible by the user. Highly flexible automatic assembly cells, as developed to date, will therefore not succeed. What is required is a solution which, being based on several reconfigurable, task-specific elements (modules), allows for a continuous evolution of the assembly system. In order for this to succeed, however, a dynamic link to the product design process must be created.

\section{BACKGROUND}

One of the fastest growing and knowledge intensive fields of today is the telecom market, where the annual growth has been of approximately $20-25 \%$ in the past five years (1995-2000). During this time, the trend of outsourcing of whole, or parts of, products has also increased. Consequently, sub-contracting companies are constantly gaining market shares of the total value of the production. Using the benefits of manufacturing products for a number of companies, and at the same time converting the production plants from high-wage to low-wage countries, they can keep a low manufacturing cost. The trend of outsourcing does not depend on lowering manufacturing costs alone, but also on the growing importance for the telecom companies to focus on their core-competence, which is the telecom technology and not manufacturing.

This trend of outsourcing has dramatically changed the production chain development - customer. To simplify, one can say that the traditional chain consisted of Development/Design - Manufacturing - Customer, in which both Development/Design and Manufacturing were in-house and located in the same 
country as the company itself. Today, the chain consists of Development/Design New Product Introduction (NPI)/Industrialization - High Volume Manufacturing Customer, in which Development/Design and NPI/Industrialization are located inhouse and in the same country, whilst the high volume manufacturing is outsourced and located in so called low-wage countries (see fig. 1).

Consequently, the "home" country is left with a low-volume production of many variants in the early phase of the product life cycle. Unfortunately, during such early phases, the knowledge of the product and associated assembly processes are low.

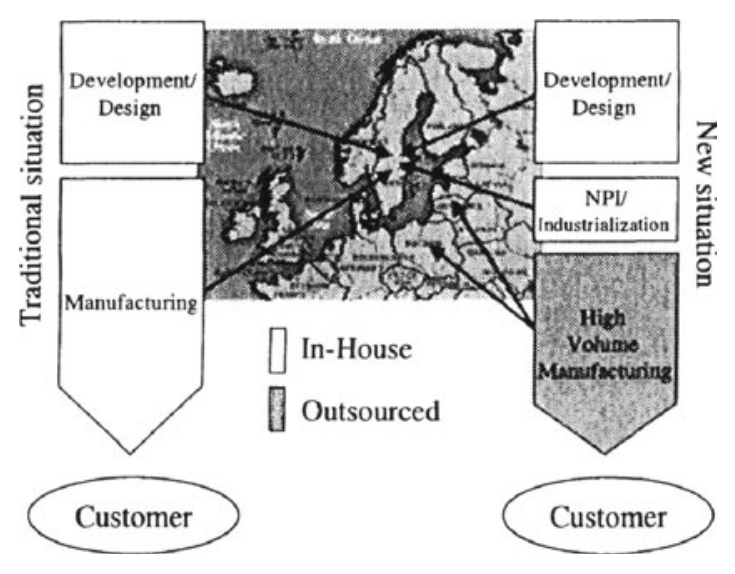

Figure 1 - TheTrend of Outsourcing

It is therefore important to analyse the functional requirements created by the outsourcing trend. This is particularly vital for final assembly systems of an NPI / Industrialization plant in the telecom market, in which the cycle NPI - volume production - Transfer Product Introduction (TPI) cycle restarts every $20-30$ months. NPI is hereby the term used to denote all activities in a product development project, from assignment to achieved project targets (time, quality and cost), that are intended to assure production capacity, produceability and the ability to deliver market volumes at the right time, cost and minimal environmental impact (see fig. 2). 


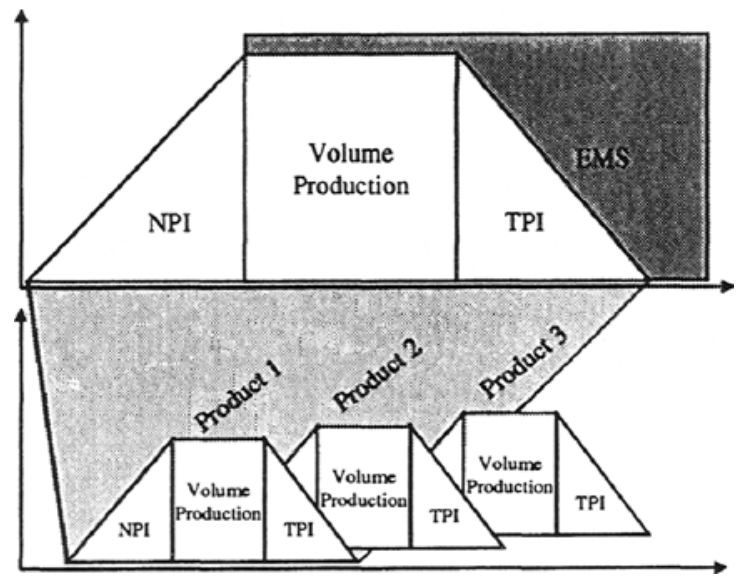

Figure 2 - NPI, Volume Production and TPI

The Assembly Module Platform (AMP) described in this article aims to create the necessary prerequisites for how to become a world-class NPI/Industrialization manufacturer.

\section{THE FUNCTIONAL REQUIREMENTS}

The project has defined the following production characteristics as targeted problem areas :

- Time-To-Market (TTM), the time to introduce new products to the market [7]. It has been found that $80-90$ percent of the TTM equation is absorbed in the design phase [8]. Therefore, a tool that could optimise the collaboration between designers and manufacturers is urgently needed. The tool should aim at reducing the designing time and, at the same time, render the design more process-oriented.

- Ramp-up, after a successful introduction of a new product, the demand of the product tends to rapidly increase and companies are often unable to close the gap between supply and demand. Therefore, it is of great importance to shorten the Time To Volume (TTV): the time it takes to reach the targeted supply capacity. Due to economical reasons, as important is obtaining a short Time To Break-even (TTB): the time taken by the product to begin generating a profit (see fig. 3).

- Market fluctuations, demand fluctuations that follow the economic climate, customer strategies etc. These fluctuations may vary in depth and length, and can be very irregular and unpredictable.

- Re-useability of equipment, The time that a product is assembled in the plant is too short to alone carry the cost of an investment in an automatic assembly system [9]. Furthermore, re-using the equipment creates a great possibility to gather process knowledge, and, as described later on, create design guidelines[10]. 
- Large number of product variants, in the early phase of the product life cycle, in which the knowledge of the product and associated assembly processes are low.

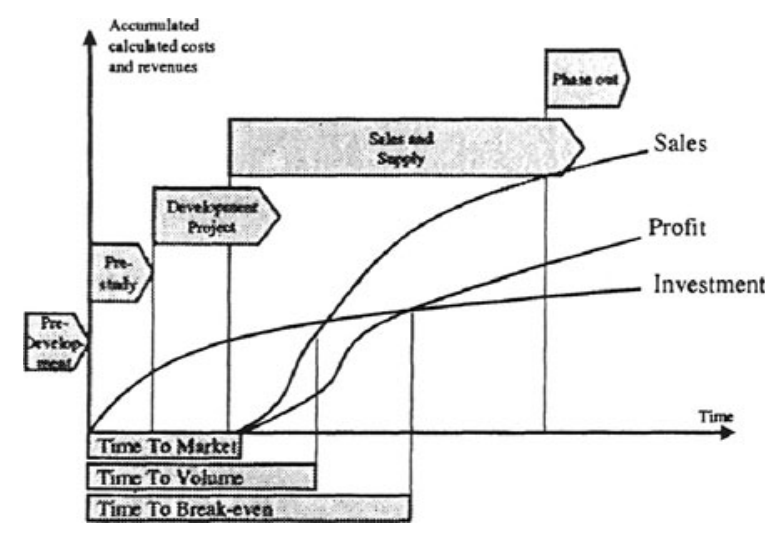

Figure 3 - The Importance of Rapid Output Increase of Production Volume

These demands call for specific assembly system properties. These properties may be summed up within the following functional requirements:

- Capacity flexibility, the ability of an assembly system to react to changing market demands in terms of the quantities asked for [11]. Vital for the adequate absorption of market fluctuations and ramp-ups.

- Capability flexibility, is the ability of an assembly system to react to changing market demands in terms of product variants asked for [11].Vital for the adequate absorption of market fluctuations and large product variant floras.

- Process robustness. Vital for true flexibility, quality levels, and the efficient re-use of equipment.

\section{THE AMP APPROACH}

Due to the demands and functional requirements stated above, a new approach to flexible assembly systems design and process-oriented product design, suited for the NPI-environment in the telecom market, is being developed in a long-term project that started January 2001. The project is carried out in collaboration between The Royal Institute of Technology, the WoxénCentrum, and Ericsson.

In the following section, the Assembly Module Platform (AMP) is introduced as the heart of the approach. The process-driven product design guidelines are also presented, as well as the motivations and prerequisites for standardisation. 


\subsection{The Architecture of the Method}

A well-structured Assembly Module Platform (AMP) is currently being finalised, in which all the required assembly processes are well structured and defined, along with the specific equipment to enable the processes.

The creation of the AMP modules is based on these assembly processes. This enables a process-oriented product design since the available technological solutions are known a' priori to the start of the product design [12]. Since the design of the product is carried out on the basis of given assembly modules, one may evaluate the influence of different product designs on the assembly system and compare the different assembly system configurations which ensue, thus giving a comparative list of investment costs, assembly costs, annual production volumes, etc. For this purpose, an economical evaluation tool is also being developed for the AMPdatabase, in which one may select and compare different assembly system configurations and, thereby, also the product design.

The basic notion, or paradigm, in this project is the belief that extreme and longlasting flexibility cannot be achieved without a distinct connection between product design and the assembly system, using standard process-oriented modules [13].

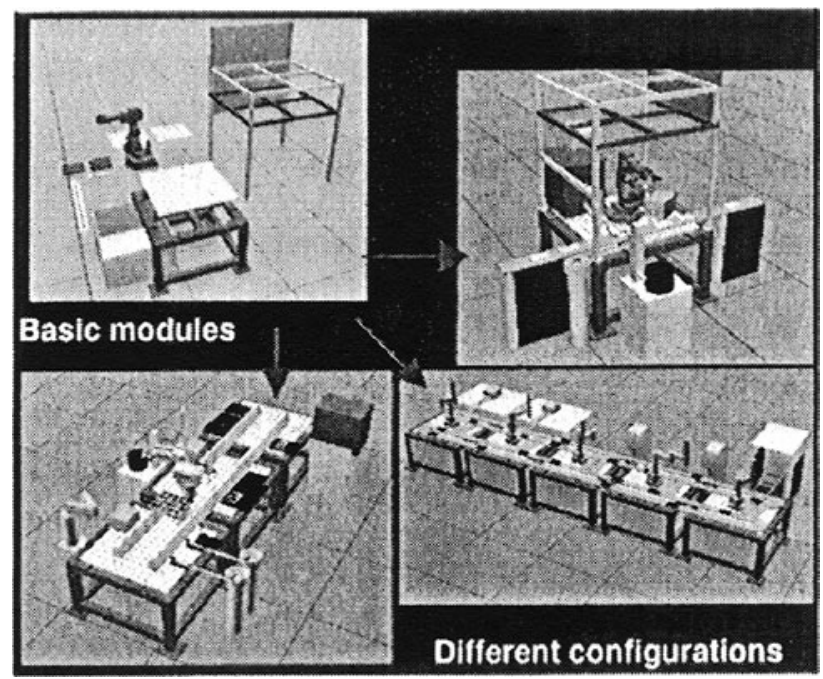

Figure 4 - The HFAA Module Concept

In order to achieve the full level of flexibility, assembly solutions must be designed to integrate any form or type of equipment: truly standardised interfacing. The equipment, in turn, must be broken down into smaller, process-oriented components. This approach [10], which allows for a stepwise automation and knowledge acquisition, requires an in-depth study, classification and structuring of the assembly process and its requirements. Once the process requirements are classified, an assembly concept which consists of small, targeted components rather than multipurpose cells, will be attainable. This represents a shift in thinking since it implies that theoretically very flexible, multi-purpose cells will be replaced by a highly 
flexible concept consisting of several well-targeted but not, in themselves, highly flexible components. Hence the new project paradigm. This is in full accordance with the Hyper Flexible Automatic Assembly project (HFAA), and enables the defining of the required assembly processes a' priori to the product design. The paradigm will probably redefine some of the older focuses on flexibility. For instance, achieving product flexibility through flexible equipment has been an established goal for some time, by attempting to create equipment so flexible that it could handle almost any products or variants. However, in this project, capability flexibility is achieved through process structuring and connections to the product design.

One of the main objectives of FAA research has been the development of systems with high product flexibility ([14],[15]). The industry has, however, been very reluctant to invest in such solutions. Therefore, should the given paradigm be correct, all projects concerned with the assembly system alone, without considering the connection between the assembly processes and the product design, are assumed to fail.

\section{THE ASSEMBLY MODULE PLATFORM (AMP)}

The AMP is a structured platform containing standardised process-oriented modules, for use within the telecom market. The AMP consists of five levels, based on: Process-class, Cell-Module, Module, Attribute and Parameter (see fig. 5).

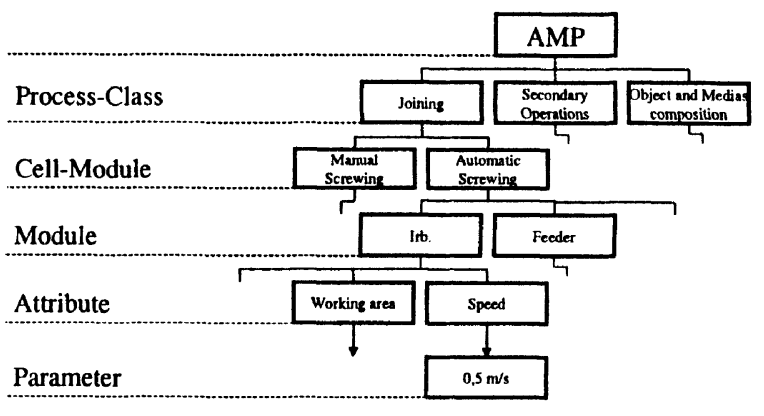

Figure 5. The AMP Structure

The definitions of the different levels are as follows:

Process-class:

A group of similar processes.

Process:

An activity that, together with other activities in the assembly system, refines parts and base-objects into a finished product. E.g. Type B soldering .

Cell-module:

A cell, or cluster of equipment, with a specific task that creates a complete building block in the assembly system. Consists of one or more modules that, through their combinability, can create a specific configuration of a cell-module. E.g. Automatic laser marking. 
Module:

A combinable equipment/component that fulfils a certain functionality within the cell-module by working with other modules through standardized interfaces, then called sub-modules. E.g. Assembly robot.

Attribute:

Characteristics of a module or sub-module. E.g. Acceleration, workspace, repeatability, etc .

Parameter:

A value or range of values of an attribute. The design of the parameter should allow that the sum of the attributes, with its specific parameters, will give a complete definition of the module: the so-called Module Process Definition (MPD).

The AMP consists of three process-classes: object and media compositions, joining, and secondary operations. These are defined as follows:

Object and medias composition:

Picking, possible manipulation, and orientation of parts (in object or medium form) and base-object, whereafter insertion is performed.

Joining:

Picking, possible manipulation, and orientation of parts and base-object, whereafter fixation with one process method occurs.

Secondary operations:

Activities not in the actual value adding chain, but necessary before delivery.

Three objectives have been focused upon during the development of the AMP :

- First, the cell-modules should be at such a level that they may easily be seen as building blocks in the total assembly system, for example by performing a distinct process (e.g. an automatic soldering cell).

- Secondly, each cell-module should consist of a number of modules that, through their combinability, could create different re-configurations of the cell-module (e.g. a screwdriver or an assembly robot).

- Thirdly, each module should facilitate the complete definition of the executed assembly process. Basically, an inherent guideline for product designers and production engineers can be formed by the cell-module configuration procedure.

One can say that adding or subtracting cell-modules enables capacity flexibility, and, likewise, shifting modules in a cell-module enables capability flexibility.

\section{THE GUIDELINES}

In the AMP, the attributes and the parameters represent the two lowest levels. Together they generate the Module Process Definition (MPD), which fully defines each specific module's performance, geometrical abilities, etc. As the attributes can be divided into attributes affecting product design, and attributes affecting production engineering, two different guidelines can be generated: 
- the product design guidelines, enabling a process-oriented product design in which the assembly process carried out by the assembly equipment is known a' priori to the product designer.

- the production engineering guidelines enabling a comparison of configuration costs, annual volumes, etc..

Since the guidelines will give a complete definition of the assembly process, the design of the product is well suited for the NPI-equipment, and can easily be introduced to the assembly system. Since the parameters are based on both today's equipment and future product demands, and are constantly updated, the guidelines create a process-oriented product design that is modern at all times and enables a long term capability flexibility.

\section{THE STANDARDIZATION ASPECTS}

Due to the importance of re-use of equipment and a high (re-)configuration ability of the system, all modules in the platform should be standardised, including the interfaces. Many definitions of standardisation have been given in the literature, none of which, however, fulfil the needs of this project.

Note that the standardisation being mentioned here relates to the creation of assembly equipment which has been developed out of a stringent classification and structuring of the assembly process. The solution refers to an open system into which new equipment may be brought as long as it follows the delimitations and interfacing requirements.

The benefits to be gained from a standardised solution are many, amongst which one may name the following:

- Shorter installation times.

- Lower investment costs and related risk factors.

- Simpler re-configurations of original layout.

- Second-hand market for equipment.

This entails that mechanical, electrical, pneumatic, electronic and software interfaces must be standardised, be of a common format, description, etc., and allow the transport of the particular medium (software, air, etc.) without adjustments. This also entails that the physical dimensions of the particular equipment are such that the unit may be inserted into any assembly system without requiring particular modifications.

For this purpose, standardisation guidelines have been developed, consisting of six elements that together define the standardisation levels required. The elements in the matrix are:

- Documentation

- Availability

- Recognition

- Update

- Validity

- Sector management 


\section{RELATED WORK}

The approaches described above, including the AMP and the standardisation objectives, clearly point out that a single isolated effort will not succed. The project has therefore entered close collaboration with two other national and international projects in order to attain the intended goals.

\subsection{Hyper Flexible Automatic Assembly (HFAA)/ PROPER Project}

The HFAA ([9],[11]) project was initiated in order to meet the future assembly demands being posed by industry in general, and European SMEs in particular. In order to do so, a structured approach to the assembly process itself lies at the core of the project. The project is being carried out at the Royal Institute of Technology (KTH) with close industrial cooperation.

The HFAA project is being partially financed by PROPER (Programme for Production Engineering Research) and industry. The HFAA project will deal with four distinct project areas:

- Analysis of the assembly process and its interactions with product design and assembly equipment.

- Analysis of mini-assembly requirements and its requirements .

- Study of assembly factories concerned with mass customisation.

- Development of a standardised, modular, hybrid assembly system concept.

The final objective is to create a modular, HFAA system concept which consists of standardised assembly system components. Details may be found in the literature ([12],[15]).

\subsection{Assembly Net (EC Project)}

The prime aim of the Assembly Net Thematic Network [16] is to establish a well coordinated and effective support infrastructure throughout Europe in order to create a network in which existing national and international projects, and available solutions, are linked to urgent industrial needs.

The critical technologies to be brought into focus include assembly system component design, system design tools, control systems, assembly process analysis, mini and micro assembly developments, etc. The partners propose to set up the following activities:

- At least one conference per year.

- The distribution of a Newsletter twice a year.

- Organise workshops (defined by Special Interest Groups).

- Offer summer courses in theoretical (academia) and practical (industry) topics.

- Create and maintain an official website in which all of the above are listed, as well as links to existing projects, project partners and associated companies.

These activities are to be seen as a first stage of events. The aim is to broaden, in due time, the scope of activities to include the entire lifecycle of such products. The main objectives are:

- To analyse trends and provide a strategic vision on Assembly Automation. 
- To act as a catalyst for the implementation of innovative practices by industry.

- Assist partners in finding funding sources, educational resources, etc.

- To provide a forum for developing focused initiatives and collaboration.

- To collect and present knowledge on Assembly Engineering to the industrial and academic community.

- A stimulus for the development of new initiatives, actions, and projects.

- The proposed Consortium currently consists of over 25 institutes from over 10 countries. Orchestrated by the foremost academic institutions in Europe, it intends to merge several national \& international research forums and already includes a vast number of industrial members. The Assembly Net (http://www.assemblynet.org ) has already succeeded in forming five specific Special Interest Groups.

\section{ACKNOWLEDGEMENTS}

The project has full access to state-of-the art assembly equipment for its development work. This equipment has been made available to the Woxén Centre by Ericsson.

\section{REFERENCES}

1. Arnström, A.; Gröndahl, P.;“Advantages of Sub-Batch Principle in Flexible Automatic Assembly as used in the IVF-KTH Concept MARK II"; Annals of the CIRP Vol.37/1/1988.

2. Fujimori;T. ;" Effectiveness of Factory Automation which Leads to Value Added ManufacturingSONY's Case with the Super SMART System"; Proceedings of the 25th Int. Symposium on Industrial Robots (ISIR), Hannover, Germany 1995;pp.13-20.

3. Johansson, R.; "Implementation of Flexible Automatic Assembly in Small Companies"; PhD. Thesis, The Royal Institute of Technology; Sweden, Autumn 2001.

4. Meijer,B.; Jonker,P.;"'The Architecture and Philosophy of the DIAC"; Proceedings of the IEEE International Conference on Robotics and Automation;Sacramento, California, USA, 1991.

5. Heilala,J., Voho,P.;"Agile and Reconfigurable Flexible Semiautomatic Assembly Systems"; Proceedings of the 30th Int.Symposium on Industrial Robots (ISR); Tokyo, Japan, 1999; pp.511517

6. Karlsson A, Onori M.; "A New Approach to Customer-Oriented Production"; Proceedings of the $33^{\text {rd }}$ CIRP International Seminar on Manufacturing Systems. Stockholm. Sweden. 5-7 June. 2000.

7. Pawar, K. S. et.al.; "Time to Market, Getting goods to market fast - and first", Integrated Manufacturing Systems, Vol 5 No. 1, 1994, pp 14-22

8. Charney, C.; "Time to Market. Reducing Product Lead Time", Society of Manufacturing Engimeers, Dearborn, MI, 1991

9. Alsterman, H.; Bergdahl,A.; Onori,M.; "Standardised Assembly Solutions for Secure Introduction of New Products"; Proceedings of the ISR2001, 32nd Int.Symposium on Robotics (ISR), Seoul, Korea, April 2001.

10. Tichem, M.; "Position report on flexible assembly automation", Laboratory for Production Engineering and Industrial Organisation, Delft University of Technology, Landbergsstraat 3, NL2628 CE Delft, The Netherlands.

11. Johansson, R.; "Implementation of Flexible Automatic Assembly in Small Companies"; PhD. Thesis, The Royal Institute of Technology; Sweden, Autumn 2001.

12. Onori, M.; Alsterman, H.;"Hyper Flexible Automatic Assembly, Needs and Possibilities with Standard Assembly Solutions"; Proceedings of the 3rd World Congress on Intelligent Manufacturing Processes \& Systems, June 2000, Cambridge, Ma.,USA. 
13. Vos, J.A.W.M.; "Module and System Design in Flexibly Automated Assembly"; Ph.D.Thesis, TU Delft, The Netherlands, DUP Science. ISBN 90-407-2195-5

14. Sanderson, S.; Uzumeri, V.; " Managing product families: The case of the SONY Walkman"; Research Policy 24, 1995,761-782,Rensselear Polytechnic Institute, Troy,NY 12180,USA.

15. Onori, M.; Alsterman, H.; Bergdahl,A.; Johansson,R.; "The Hyper Flexible Automatic Assembly Concept Application: MarkIV"; Proceedings of the Delft Workshop on Assembly Automation, Delft, Holland, May 11-12, 2000.

16. Onori, M.; Sandin, E.; Alsterman, H.; "European Assembly: Threats and Counter-Measures"; Proceedings of the 2nd IFAC Workshop on Intelligent Assembly and Disassembly (IAD'2001), Gramado, Brazil, November 2001; Elsevier Press. 